\title{
Prediction of permeability and its anisotropy of tight oil reservoir via precise pore-throat tortuosity characterization and "umbrella deconstruction" method
}

\author{
Shuheng $\mathrm{Du}^{*}$ \\ State Key Laboratory of Nonlinear Mechanics, Institute of Mechanics, Chinese Academy of Sciences, Beijing, 100190, China
}

\section{A R T I C L E I N F O}

\section{Keywords:}

Tight oil

Permeability

Pore-throat tortuosity

"Umbrella deconstruction" method

\begin{abstract}
A B S T R A C T
This study aimed to investigate the prediction method of permeability and its anisotropy of tight oil reservoir via precise pore-throat tortuosity characterization and "umbrella deconstruction" method combining the approaches of the field emission SEM imaging, high resolution image processing, fine and large-scale mathematical statistics, nonlinear regression and other technical means.

In this paper, the authors proposed the new calculation model of pore-throat tortuosity, the absolute permeability and the permeability anisotropy based on the improved deep understanding of reservoir. Results of the prediction on the tight oil reservoir of "YANCHANG" formation in Ordos Basin show that the errors of the new method in this paper are the smallest among the total five methods, respectively $0.023 \times 10^{-3} \mu \mathrm{m}^{2}$ and $0.090 \times 10^{-3} \mu \mathrm{m}^{2}$; the average values of other four methods were $0.090 \times 10^{-3} \mu \mathrm{m}^{2}$ and $0.108 \times 10^{-3} \mu \mathrm{m}^{2}$, respectively. The predicted results have higher accordance with the measured results, which proved the practicality of the new method. The samples has the highest permeability at the angle of $0^{\circ}\left(180^{\circ} / 360^{\circ}\right)$ and the permeability values are equal to $0.25 \times 10^{-3} \mu \mathrm{m}^{2}$. Similarly, the sample has the lowest permeability at the angle of $22.5^{\circ}\left(202.5^{\circ}\right), 90^{\circ}\left(270^{\circ}\right)$, and $112.5^{\circ}\left(292.5^{\circ}\right)$, the permeability values are all equal to $0.06 \times 10^{-3} \mu m^{2}$. At the same time, the calculation of permeability anisotropy results shows that the anisotropy of tight oil reservoirs is very significant, and the permeability value in one direction is obviously higher than which in other directions.

It is concluded that the precise description of pore throat geometry, especially the calculation of pore-throat tortuosity parameter, is one of the most important parameters affecting the prediction accuracy of permeability theoretically. Meanwhile, there are dominant seepage channels, which would play a very important guiding role in the prediction of hydrocarbon accumulation and seepage capacity.

The conclusion will provide a more rigorous theoretical basis for the rapid and accurate evaluation of the physical properties of unconventional reservoirs.
\end{abstract}

\section{Introduction}

Permeability, as an important parameter for evaluating the physical properties of the reservoir, largely reflects reservoir productivity level. According to the parameter of permeability, three major heterogeneities, i.e. surface heterogeneities, interlayer heterogeneities and intra-layer heterogeneities, can be derived, and the differences of reservoir and seepage levels can be described from a macro perspective, so as to achieve the goal of comprehensive evaluation of reservoir quality.

As to the permeability prediction, it was found that Beckingham et al. (2013) and other researchers compared the predicted and measured permeability values based on SEM. It was believed that the distortion of surface roughness into pore throat resulted in the underestimation of permeability. Arash et al. (2016) estimated three-dimensional coordination numbers from two-dimensional cross-sectional images and explored the error of absolute permeability prediction using pore network flow model. An et al. (2016) studied the effects of pore throat ratio, coordination number and pore throat orientation on absolute permeability using a regular network model. Shah et al. (2016) predicted the properties of pore network, such as the number of pore and throat, average pore throat radius and coordination number, and used Lattice Boltzmann (LBM) or pore network (PNM) modeling to simulate single-phase and dual-phase flow. Three-dimensional core image can be obtained after CT scanning, and digital core can be built after filtering and segmentation. Yang et al. (2016) gets the rock

\footnotetext{
* Corresponding author.

E-mail address: dushuheng@imech.ac.cn.
} 
structure characteristics by analyzing the Geometry-Topology structure of the extracted pore network model, and carries out sandstone flow analysis through numerical simulation. Patrick et al. (2017) established a porosity index and pore resistivity model to explore the permeability of carbonate rocks in northeastern Brazil. Nishank et al. (2017a, b) comprehensively assessed the differences in the solution of seepage solvers including Lattice-Boltzmann, computational fluid dynamics, voxel-based, fast semi-analysis and known empirical models. It was concluded that the main causes of the errors included parameterization of basic physical equations, differences in boundary conditions and numerical convergence criteria. The parameterization of physical equation needs further optimization. Nishank et al. (2017a, b) also studied the error of image segmentation threshold and image voxel size in calculating image permeability, and proposed a correction method between laboratory measured values and digital rock calculated values. Arash et al. (2017) respectively predicted permeability based on neural network model and empirical equation with both porosity and average coordination number, but they could not explain carbonate permeability well. Song et al. (2018) considered the size distribution combination of organic and inorganic pore, studied its influence on gas flow by numerical simulation. Kirill et al. (2018) proposed the Stokes solver (FDMSS) for three-dimensional pore geometry, which directly studies pore fluid flow simulation and permeability assessment in three-dimensional voxelized pore geometry (i.e. meshless). All the above studies show that the micro-details of reservoirs have a great impact on the theoretical prediction of permeability. In other words, the accurate description of pore throat geometry is an indispensable part of improving the accuracy of permeability prediction.

Pore-throat tortuosity is the ratio of the actual length of the seepage channels and the apparent length the fluids flow through the seepage medium (the macro distance). Fluid particles flow through the medium in unit distance-the actual length of motion trajectory of the particle; this is an important parameter for the evaluation of the complexity of the seepage channel, but also one of the most important parameters in the prediction of reservoir permeability (Lonnes et al., 2003; London et al., 2014; Arash et al., 2014; Huang and Zhao, 2017; Nishank et al. (2017a, b)).

As to the pore-throat tortuosity calculation, in the early studies, the pore-throat tortuosity was measured directly by the casting sheet, but measurement efficiency was low and accuracy was limited. In recent years, scholars have carried out a great deal of research in related fields in order to increase both the accuracy and the efficiency of such measurements. Plessis and Masliyah (1988) investigated the relationship between pore-throat tortuosity and porosity. Sen et al. (1981), Boundreau et al. (1996), Comiti et al. (2000), and other scholars tried to solve this problem based on the experimental summary. Koponen et al. (1996) used the LG numerical simulation to give the expressions of pore throat curvature and porosity in porous media, respectively. $\mathrm{Lv}$ et al. (2000) proposed gas permeability method. Yu et al. (2016) calculated the average pore-throat tortuosity by porosity based on the model of curved pipe while. Chen et al. (2011) gave an empirical equation of pore-throat tortuosity. In that equation, the tortuosity is only the function of porosity, and the form is relatively simple, but whether it is robust enough to characterize the factors of pore-throat tortuosity accurately is still questionable. However, the above estimation methods have many shortcomings: Among other issues, they include too many estimation parameters, are difficult to obtain, and the estimation mechanisms tend to be too complex.

Based on a great deal of literature research and analysis, the author thinks that the pore-throat tortuosity results measured by different methods are quite different from each other and are relatively poor in comparison; this makes the physical meaning unknown and it is difficult to verify the accuracy each of these methods when compared to the others. For example, with a capillary force test and seepage test, the randomness of sampling direction and the random starting position of the flow could have randomized the seepage results, so the test results of a single sample or a low number of samples represent only a single or a small number of pores and throats through which the fluid flows, but it cannot accurately and consistently reflect the overall features of reservoir space. In addition, due to the brevity of the seepage test, the unreliability of the experimental results is further exaggerated. This is somewhat similar to the limitations of the high-pressure mercury pressure test. Similarly, pore-throat tortuosity measurement methods of image processing are mostly concentrated in the manual measurement based on the cast slice images under the polarizing microscope. It may cause the lack of automation program, and the measurement process has built into it a certain randomness, so the limitation is obvious: A simplified estimation model of the pore-throat is too idealistic, so the accuracy of the calculated result is worth considering (Piela et al., 2009; Peng et al., 2011; Rajkumar et al., 2012; Beckingham et al., 2013; Ren et al., 2015; Kenneth et al., 2018).

As is obvious in the above research, most of the pore-throat tortuosity estimation methods focus on experimental testing and simplified modeling, and the majority of experimental and numerical simulation methods treat the reservoir with high porosity and medium permeability as the research object. Thus, the numerical simulation of the Koponen method could be used only for a reservoir exhibiting a porosity higher than $33 \%$. Results of the other studies could only be used for a reservoir with a porosity higher than $15 \%$. For the tight sandstone reservoir, more effective estimation methods were still lacking. Is the pore-throat tortuosity of the tight sandstone reservoir only controlled by the single factor of porosity? This has also not been reported in the literature. In addition, accurate estimation methods based on the concept of the original pore-throat tortuosity are still few, the reservoir pore-throat tortuosity estimation methods used are still not stringent and their results remain unclear (Rhiannon et al., 2016; Shah et al., 2016; Rikan et al., 2017; Song et al., 2017; Yang et al., 2017).

Based on these limitations, a new pore-throat tortuosity estimation method is proposed so the new permeability prediction model is also proposed in this paper.

In addition, the anisotropy of reservoir permeability is also an important issue of great concern in petroleum geology and engineering. If we want to predict the anisotropy of permeability, we must firstly understand the development of pore throats and minerals in all directions of reservoir, and the conclusion should be representative, that is to say, the observation scale should not be too small. "Umbrella deconstruction" technology is a new technology proposed by Du et al., in 2018 to accurately characterize the heterogeneity and anisotropy of pore throats and minerals in unconventional oil and gas reservoirs on a large horizon scale. This method takes the lead in alleviating the contradiction between resolution and observation scale of unconventional reservoir in two-dimensional space. This paper intends to combine this method to study the heterogeneity of reservoir permeability.

In this paper, we followed the original characteristics of the reservoir, then closely focused on characteristics such as pore size, structure and so on. In accordance with our goal of accurately describing the pore and throat in the full range, we calculated the porethroat tortuosity of the unconventional reservoir under the multi-scale, and applied the tortuosity values to the fast prediction of matrix permeability in an unconventional sandstone reservoir in Ordos Basin, China, using the extension form of Kozeny-Carman equation. At the same time, "umbrella deconstruction" was carried out for tight oil reservoirs, and quantitative prediction of permeability anisotropy of tight oil reservoirs was also carried out in combination with the new porethroat tortuosity calculation method and permeability prediction model proposed in this paper.

\section{Geologic setting}

The Ordos Basin is located in the western part of the north China landmass (Fig. 1). It is a large multicycle craton basin with the occurrence of whole lift and depression migration, and the structure inside 


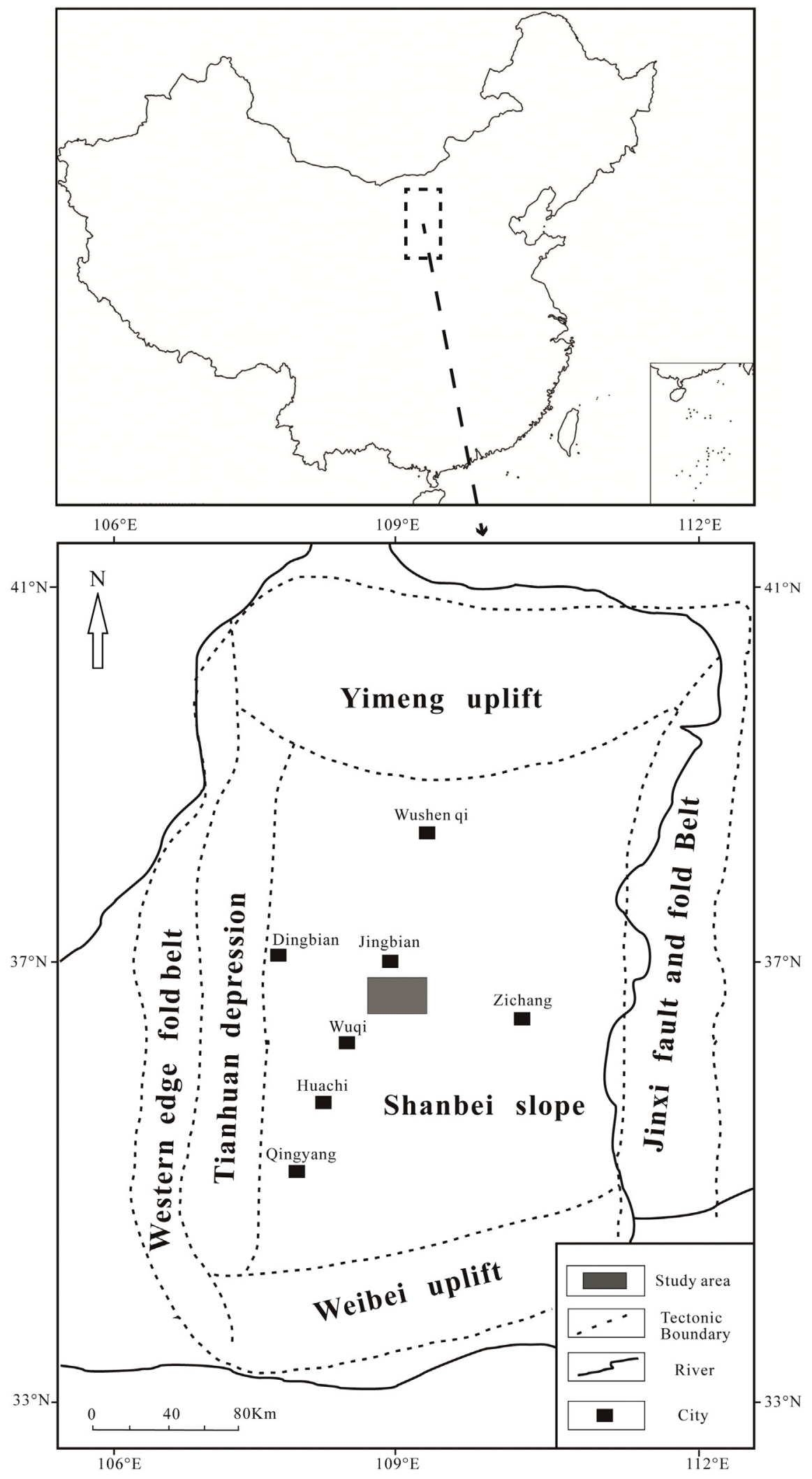

Fig. 1. Location of study area in Ordos Basin, China (Du et al., 2019).

the basin is relatively simple. Abundant oil resources existed in the Upper Triassic the ultra-low permeability Yanchang Formation, which is part of a lake-delta sedimentary system (Du et al., 2018a and 2018b).

The study area is located in the southwestern part of the northern Shanxi slope in the Ordos Basin. The "YANCHANG" formation belongs to the clastic rock dominated by lacustrine sediments in Late Triassic. The physical properties are poor, the average porosity is $8.85 \%$, and the permeability is $0.16 \times 10^{-3} \mu \mathrm{m}^{2}$. The pore types are mainly intergranular pore and dissolved pore; the primary inter-granular pore, secondary inter-granular pore and secondary dissolved pore are 


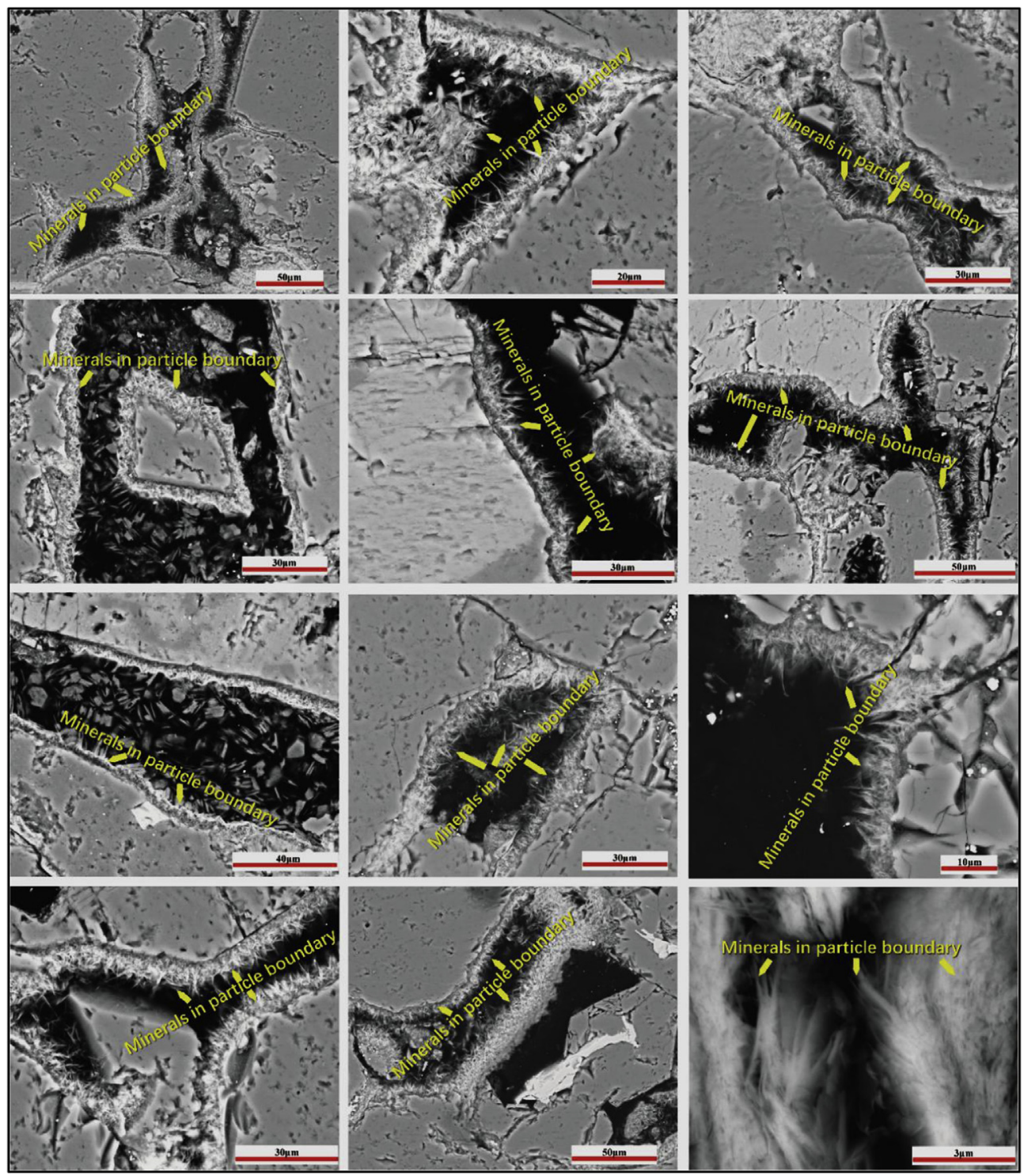

Fig. 2. SEM observation of the minerals in the particle boundary in an unconventional reservoir.

relatively developed (Xiong et al., 2016).

\section{Methods and principles}

\subsection{Methods development of permeability prediction}

First of all, it is necessary to point out that understanding the fluid flow in porous media, especially the micro-nano pore-throat, is an extremely complex issue. The influencing factors focused mainly on three aspects: the fluid properties (Newtonian or non-Newtonian), porethroat characteristics (size, direction, tortuosity and mineral types in the pore-throat boundary), and interaction between fluid and minerals in the particle boundary (physical adsorption, chemical corrosion and so on) (Fig. 2).

Therefore, the macro distance of the fluid motion can be easily determined, but the actual streamline is far more complex than the macro trajectory; such things as the fluid reflux could make measurement difficult. When we use the "pore-throat divide-union" method to calculate the pore-throat tortuosity, the fluid reflux is fully considered in the equation. When we compared development characteristics of the pore-throat with those of the river channels in the later periods (such as a meandering river and a braided river), we saw that the bending outer boundary of the pore-throat would cause the streamline dispersion and fluid reflux should be carefully observed. Therefore, after full consideration of the diversity and complexity of pore-throat distribution and the real streamlines, we use the " $n$ " times of pore-throat perimeter (" $\mathrm{n}$ " is determined by the actual flow process and it could be any positive value) to indicate the actual flow distance of the fluid flowthrough, which can greatly highlight the diversity and energy consumption in the process of seepage, and is thus more practical.

Kozeny (1927) and Carman (1939) proposed Kozeny-Carman equation (KC equation) based on capillary bundle model, namely:

$K=\frac{\varphi^{3}}{C S^{2}}$

In equation (1), " $K$ " indicates the permeability, the unit is " $10^{-3} \mu \mathrm{m}^{2}$ "; " $\varphi$ " indicates the porosity, the unit is "\%"; " $S$ " indicates the surface area, the unit is " $\mathrm{m}^{2}$ "; " $\mathrm{C}$ " indicates the $\mathrm{KC}$ constant, which is generally considered to be related to pore-throat tortuosity. KC equation could obtain the pore and permeability parameters in spatial sense based on the infinitesimal element volume analysis method, which solves the problem of theoretical prediction of permeability to a certain extent. Researchers have found that the KC constant is closely related to the micro-pore structure of porous media, so many methods have been 
used to modify the KC equation. However, this does not mean that all the problems on theoretical prediction of permeability have be solved. When we use equation (1) to calculate permeability, the acquisition of $\mathrm{KC}$ constant is still an important bottleneck problem, but there is still no good calculation method for this KC constant related to pore-throat tortuosity at present, which leads to the theoretical prediction accuracy of permeability still has room for improvement.

In order to predict permeability more conveniently and quickly, $\mathrm{Li}$ and Zhang (2007) gave a simplified generalization of KC equation according to the unified model of pipe flow and seepage flow which is:

$K=\frac{\varphi r^{2}}{8 \tau}$

In equation (2), " $\varphi$ " indicates the porosity, the unit is "\%"; " $r$ " indicates the pore radius, the unit is " $\mu \mathrm{m}$ ", " $\tau$ " indicates the pore-throat solidity.

Taking equation (2) as an example, we can think about the problem that if we get the exact value of each parameter in this equation, then the permeability can be calculated accurately to a large extent. Equation (2) involves three variables, the porosity $(\varphi)$, the radius of capillaries $(r)$ and the pore-throat tortuosity $(\tau)$. As to the reservoir sample, if the pore throat structure is obtained by high precision imaging technology, the porosity $(\varphi)$, and the radius $(r)$ of capillaries were all easily obtained parameters. However, many methods could obtain the porethroat tortuosity but the accuracy is difficult to control so it needs to be studied emphatically.

In a word, the accuracy of permeability prediction depends on the accuracy of pore-throat tortuosity parameters.

\subsection{Assumptions of the new method}

The assumptions of the new method is mainly based on the establishment of a new theoretical model of pore throat and the new understanding of the original definition of pore -throat tortuosity. SEM observation on the unconventional reservoir shows (Fig. 2) that the minerals in the particle boundary could be widely found under the microscope. In order to figure out the mineral type, element analysis on the minerals in the particle boundary has also been done (Table 1). The result of that analysis shows that illite plays the most important role in the particle boundary. With the growth of these minerals in an unconventional reservoir, the shape of the pore-throat could become more complex. The significance of these minerals, which grow in the particle boundary in the fluids' seepage process, should never be ignored. We should pay much more attention to this point when we investigate the precise method of permeability estimation of the unconventional reservoir.

Table 1

Element analysis on the minerals in the particle boundary in an unconventional reservoir.

\begin{tabular}{llllll}
\hline Elements $\backslash$ Sample number & 1 & 2 & 3 & 4 & 5 \\
\hline $\mathrm{C}$ & $29.64 \%$ & $70.77 \%$ & $29.08 \%$ & $32.58 \%$ & $10.59 \%$ \\
$\mathrm{Na}$ & $0.14 \%$ & 0 & 0 & 0 & 0 \\
$\mathrm{Mg}$ & $0.11 \%$ & $0.53 \%$ & $2.63 \%$ & $0.42 \%$ & $5.77 \%$ \\
$\mathrm{Al}$ & $1.03 \%$ & $2.06 \%$ & $6.03 \%$ & $4.82 \%$ & $5.23 \%$ \\
$\mathrm{Si}$ & $1.82 \%$ & $2.52 \%$ & $8.27 \%$ & $7.20 \%$ & $9.25 \%$ \\
$\mathrm{~K}$ & 0 & 0 & $0.28 \%$ & $1.41 \%$ & $1.55 \%$ \\
$\mathrm{Fe}$ & $1.27 \%$ & $1.76 \%$ & $2.11 \%$ & 0 & $3.74 \%$ \\
$\mathrm{O}$ & $65.93 \%$ & $22.26 \%$ & $51.60 \%$ & $53.35 \%$ & $58.52 \%$ \\
$\mathrm{~F}$ & 0 & 0 & 0 & 0 & $5.00 \%$ \\
$\mathrm{Ti}$ & 0 & 0 & 0 & 0 & $0.35 \%$ \\
$\mathrm{Cl}$ & $0.06 \%$ & $0.10 \%$ & 0 & $0.22 \%$ & 0 \\
$\mathrm{Mineral} \mathrm{Type}$ & Illite & & & & \\
\hline
\end{tabular}

\subsection{Solutions of the new method}

Fig. 3 is the diagrammatic sketch of single pore-throat tortuosity estimation after considering the minerals in the particle boundary. According to the seepage theory, the fluid would flow through all connected pore-throats when the fluid flows in every direction and the percolation process continues for a long enough time.

The estimation method is as follows. First, we calculated the perimeter of single pore-throat (boundary length of a single pore-throat), and the average perimeter of all the pore-throats that could be obtained. Then, in order to obtain the apparent length (i.e., the macroscopic distance) of the fluid flowing through, we set up the related program, and conducted the Legendre ellipse fitting for the single porethroat, generating the average long axis length of the Legendre ellipse of all pore-throats. Finally, according to the definition of pore tortuosity, when fluid flows through the pore-throat, the pore-throat tortuosity is the ratio of $\mathrm{n}$ times the average pore throat perimeter and the average the major axis length of the Legendre ellipse.

The concrete equation is as follows:

$\bar{\tau}=\frac{n \overline{\mathrm{P}}}{\overline{L_{a}}}$

In equation (3), " $\bar{P}$ " indicates the average perimeter, the unit is $\mu \mathrm{m}$; " $n$ " indicates constants Ce with the original properties of reservoir, dimensionless; " $\overline{L_{\mathrm{a}}}$ " indicates the average length of major axis of the Legendre ellipse, dimensionless.

The equation (3) is the estimation equation of single pore-throat tortuosity. Because the whole reservoir consists of thousands of porethroats, the parameters in the above equation are all the average values, so the final result is the average pore-throat tortuosity.

\subsection{Prediction of permeability with high efficiency}

Taking the SEM and CT images of the tight sandstone reservoir as the original data, image processing should be carried out (Fig. 4). First we use the inter-modes algorithm to calculate the threshold of each image (Fig. 4-(1)). Second, we extract the pore-throat (Fig. 4-(2)). Third, a discrete single pore-throat is taken to calculate the tortuosity of the single pore-throat. (This step indicates the "divide" in the "porethroat divide-union.") Last, we calculate the average value of all the pore-throats, treating this value as the final tortuosity of the reservoir. (This step indicates the "union" in "pore-throat divide-union.")

The equation (2) shows that the pore-throat tortuosity $(\tau)$ is a rather important unknown parameter in the KC equation used to calculate the permeability. Therefore, the reasonable estimation of the pore-throat tortuosity, combined with the statistical estimation of the pore-throat parameters, can be effectively applied to the prediction of the reservoir permeability. When we put equation (3) into (2), we get the final equation of permeability estimation (Equation (4)).

$\bar{K}=\frac{\varphi \bar{r}^{2} \bar{L}_{a}^{2}}{8 n^{2} \bar{P}^{2}}$

In equation (4), “ $\bar{r}$ ” indicates the average pore-throat radius, the unit is $\mu \mathrm{m}$.

\subsubsection{Permeability anisotropy determination when combing "umbrella deconstruction" method}

The steps of the "umbrella deconstruction" method" are like followings (Fig. 5). First, we drilled the standard core sample of the tight oil reservoir. Second, we draw 8 remarkable lines every $22.5^{\circ}$ in the overlook surface of the sample. Third, we cut the thin sections along the 8 lines. Fourth, we use the FE-SEM instrument to characterize the reservoir in 8 thin sections and get the images with high resolution. Fifth, we use the new and more precise theoretical model to predict the permeability of 8 thin sections. Finally we could draw the curve of the permeability changing with angels and evaluate the microscopic 


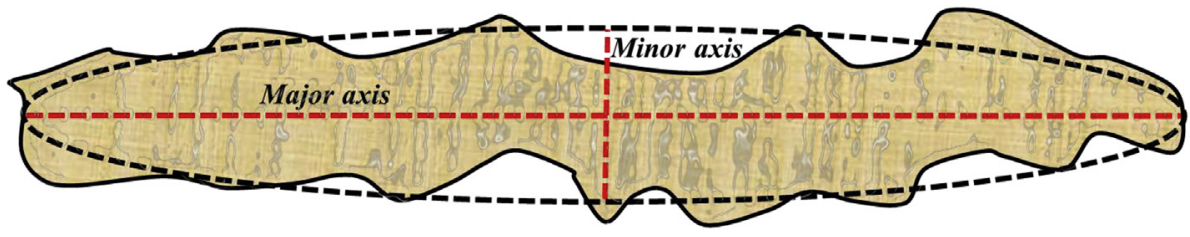

Fig. 3. Diagrammatic sketch of single pore-throat tortuosity estimation after considering the minerals in particle boundary. heterogeneity of the permeability potential in tight oil reservoir.

\subsection{Simplified form of the new permeability prediction model}

In order to predict the permeability more rapidly and increase the applicability of the new model, we need to discover the simplified form of the new permeability prediction model proposed in this study which means that as long as we get some general parameters like porosity of the reservoir, we could get the precise value of its permeability.

In order to achieve the above goal, we combined field emission SEM imaging, the pore throat theory model, high resolution image processing, fine large-scale mathematical statistics, nonlinear regression and other technical means to predict the permeability of the unconventional sandstone reservoir of the "YANCHANG" formation in the Xin'anbian area, Ordos Basin, China. Results showed that the predicted results have a higher accordance with the measured results, which proved the practicality of the new method. This approach will provide a more rigorous theoretical basis for the rapid and accurate evaluation of the physical properties of tight reservoirs.

We also applied four other methods proposed by domestic and foreign scholars in carrying out the pore-throat tortuosity estimation; thus we could generate five kinds of pore-throat tortuosity values. Combined with the Kozeny-Carman equation, the reservoir permeability could be predicted and five kinds of permeability values could be obtained. Then, correlation analysis between porosity and five types of permeability prediction values was carried out and five types of relationships between porosity and permeability could be obtained. Finally, the permeability could be predicted by combining the measured porosity with five types of relations between porosity and permeability, and comparison among the five prediction results and the measured permeability was performed to verify the applicability and accuracy of the new method.

Table 2 shows that, as to the unconventional sandstone reservoir "YANCHANG" formation in the Xin'anbian area, the porosity is concentrated between $1.799 \% \sim 4.833 \%$, and the average value is $3.605 \%$; the average radius of pore-throat is $5.847 \mu \mathrm{m}-8.180 \mu \mathrm{m}$, while the average value is $7.399 \mu \mathrm{m}$; the average perimeter of pore-throat in $32.631 \mu \mathrm{m}-48.325 \mu \mathrm{m}$, and the average value is $42.555 \mu \mathrm{m}$; the average length of long axis of pore-throat is $7.501 \mu \mathrm{m}-10.698 \mu \mathrm{m}$, and the average value is $9.634 \mu \mathrm{m}$.

We will compare the calculation results with those of the other four theoretical methods for calculating the pore-throat tortuosity. The computational equations of the four methods are as follows (equations (5)-(8)):

$$
\tau(\mathrm{Yu})=\frac{1}{2}\left[1+\frac{1}{2 \sqrt{1-\varphi}}+\sqrt{1-\varphi} \frac{\sqrt{\left(\frac{1}{\sqrt{1-\varphi}}-1\right)^{2}+\frac{1}{4}}}{1-\sqrt{1-\varphi}}\right]
$$
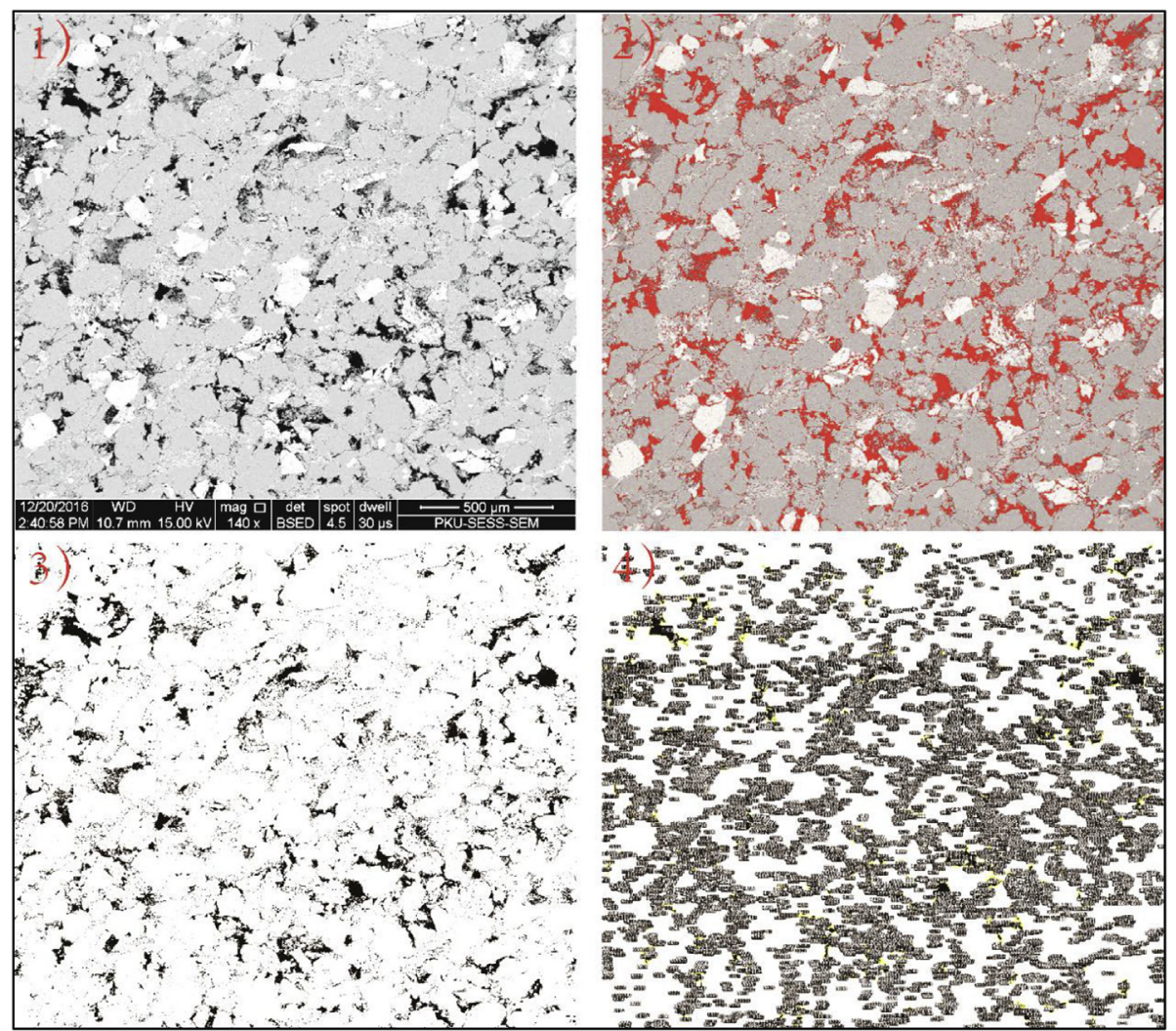

Fig. 4. Image processing process of "YANCHANG" tight sandstone reservoir.

Note: (1) source image; (2) threshold estimation; (3) pore-throat extraction; (4) parameter estimation. 

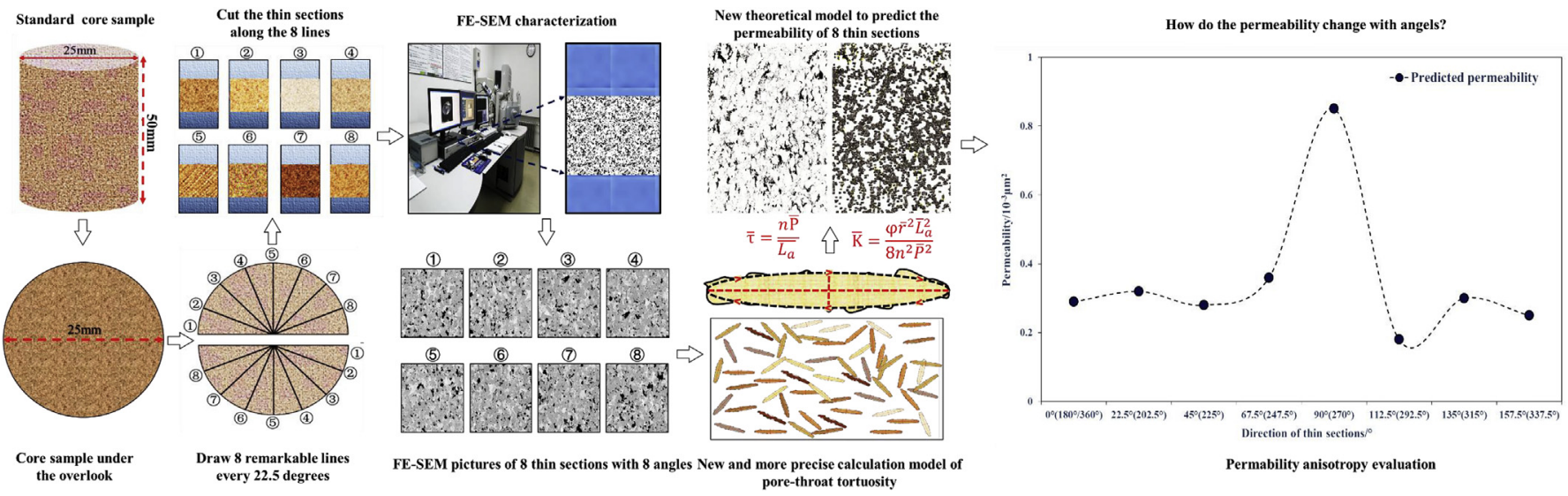

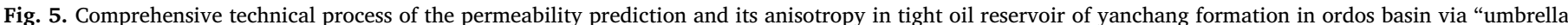
deconstruction" method and precise pore geometry characterization.

(Modified from Du et al., 2018a and 2018b).

Table 2

Test and statistics of the pore-throat parameters of the unconventional sandstone reservoir "YANCHANG" formation in Xin'anbian area, Ordos Basin, China.

\begin{tabular}{|c|c|c|c|c|}
\hline $\begin{array}{l}\text { Sample } \\
\text { number }\end{array}$ & Porosity/\% & $\begin{array}{l}\text { Average radius } \\
\text { of pore-throat/ } \\
\mu \mathrm{m}\end{array}$ & $\begin{array}{l}\text { Average } \\
\text { perimeter of } \\
\text { pore-throat } / \mu \mathrm{m}\end{array}$ & $\begin{array}{l}\text { Average semi } \\
\text { long-axis of } \\
\text { pore-throat/ } \mu \mathrm{m}\end{array}$ \\
\hline A83-1 & 4.284 & 7.720 & 43.631 & 9.937 \\
\hline A83-2 & 2.464 & 6.724 & 37.920 & 8.632 \\
\hline A83-3 & 2.528 & 6.891 & 37.923 & 8.756 \\
\hline A83-4 & 4.601 & 7.891 & 44.865 & 10.237 \\
\hline A83-5 & 3.700 & 7.282 & 42.766 & 9.551 \\
\hline A83-6 & 4.602 & 7.927 & 44.741 & 10.211 \\
\hline A83-7 & 2.219 & 6.526 & 35.854 & 8.351 \\
\hline A83-8 & 1.799 & 5.847 & 32.631 & 7.501 \\
\hline A83-9 & 4.218 & 7.572 & 42.029 & 9.756 \\
\hline A83-10 & 4.205 & 7.452 & 44.292 & 9.913 \\
\hline A83-11 & 4.833 & 8.180 & 48.325 & 10.698 \\
\hline A83-12 & 2.578 & 6.984 & 40.580 & 8.993 \\
\hline A83-13 & 3.379 & 7.397 & 40.190 & 9.604 \\
\hline A83-14 & 3.836 & 7.476 & 42.971 & 9.747 \\
\hline A83-15 & 3.560 & 7.320 & 42.909 & 9.690 \\
\hline A83-16 & 3.206 & 7.451 & 42.942 & 9.582 \\
\hline A83-17 & 3.977 & 7.434 & 42.489 & 9.678 \\
\hline A83-18 & 3.355 & 7.394 & 40.814 & 9.516 \\
\hline A83-19 & 3.683 & 7.244 & 43.113 & 9.606 \\
\hline A83-20 & 4.505 & 7.802 & 45.522 & 10.302 \\
\hline A83-21 & 3.115 & 7.430 & 41.088 & 9.588 \\
\hline A83-22 & 3.789 & 7.424 & 41.569 & 9.564 \\
\hline A83-23 & 3.355 & 7.114 & 41.193 & 9.435 \\
\hline A83-24 & 3.394 & 7.163 & 42.964 & 9.426 \\
\hline A83-25 & 4.167 & 7.602 & 45.967 & 10.064 \\
\hline A83-26 & 3.783 & 7.823 & 44.241 & 10.116 \\
\hline A83-27 & 4.000 & 7.794 & 46.321 & 10.232 \\
\hline A83-28 & 3.493 & 7.202 & 42.102 & 9.472 \\
\hline A83-29 & 2.931 & 7.064 & 41.522 & 9.195 \\
\hline A83-30 & 4.105 & 7.676 & 44.077 & 10.005 \\
\hline A83-31 & 4.033 & 7.822 & 44.369 & 10.225 \\
\hline A83-32 & 3.670 & 7.672 & 45.949 & 10.093 \\
\hline A83-33 & 3.476 & 7.216 & 42.558 & 9.507 \\
\hline A83-34 & 3.166 & 7.562 & 42.591 & 9.731 \\
\hline A83-35 & 4.176 & 7.895 & 46.409 & 10.265 \\
\hline
\end{tabular}

$\tau($ Chen $)=\varphi^{-\frac{3}{4}}-0.35$

$\tau($ Koponen $)=0.8(1-\varphi)+1$

$\tau($ Plessis $)=1+\sqrt{1-\varphi}$

In equations (5)-(8), " $\varphi$ " indicates the porosity. As can be seen in Table 3, there are obvious differences in the pore-throat tortuosity values calculated by the five methods, so there will also be differences in
Table 3

Test and statistics of pore-throat tortuosity of the unconventional sandstone reservoir "YANCHANG" formation in the Xin'anbian area, Ordos Basin, China (five methods).

\begin{tabular}{|c|c|c|c|c|c|}
\hline Sample number & $\tau$ (This study) & $\tau(\mathrm{Yu} \& \mathrm{Li})$ & $\tau$ (Chen) & $\tau$ (Koponen) & $\tau$ (Plessis) \\
\hline A83-1 & 2.195 & 12.062 & 10.270 & 1.766 & 1.978 \\
\hline A83-2 & 2.197 & 20.676 & 15.729 & 1.780 & 1.988 \\
\hline A83-3 & 2.165 & 20.162 & 15.423 & 1.780 & 1.987 \\
\hline A83-4 & 2.191 & 11.259 & 9.716 & 1.763 & 1.977 \\
\hline A83-5 & 2.239 & 13.902 & 11.504 & 1.770 & 1.981 \\
\hline A83-6 & 2.191 & 11.256 & 9.714 & 1.763 & 1.977 \\
\hline A83-7 & 2.147 & 22.915 & 17.043 & 1.782 & 1.989 \\
\hline A83-8 & 2.175 & 28.174 & 20.008 & 1.786 & 1.991 \\
\hline A83-9 & 2.154 & 12.244 & 10.394 & 1.766 & 1.979 \\
\hline A83-10 & 2.234 & 12.281 & 10.419 & 1.766 & 1.979 \\
\hline A83-11 & 2.259 & 10.738 & 9.351 & 1.761 & 1.976 \\
\hline A83-12 & 2.256 & 19.779 & 15.193 & 1.779 & 1.987 \\
\hline A83-13 & 2.092 & 15.184 & 12.338 & 1.773 & 1.983 \\
\hline A83-14 & 2.204 & 13.423 & 11.187 & 1.769 & 1.981 \\
\hline A83-15 & 2.214 & 14.433 & 11.851 & 1.772 & 1.982 \\
\hline A83-16 & 2.241 & 15.982 & 12.849 & 1.774 & 1.984 \\
\hline A83-17 & 2.195 & 12.961 & 10.879 & 1.768 & 1.980 \\
\hline A83-18 & 2.144 & 15.290 & 12.406 & 1.773 & 1.983 \\
\hline A83-19 & 2.244 & 13.964 & 11.545 & 1.771 & 1.981 \\
\hline A83-20 & 2.209 & 11.490 & 9.877 & 1.764 & 1.977 \\
\hline A83-21 & 2.143 & 16.437 & 13.137 & 1.775 & 1.984 \\
\hline A83-22 & 2.173 & 13.585 & 11.294 & 1.770 & 1.981 \\
\hline A83-23 & 2.183 & 15.290 & 12.406 & 1.773 & 1.983 \\
\hline A83-24 & 2.279 & 15.119 & 12.296 & 1.773 & 1.983 \\
\hline A83-25 & 2.284 & 12.389 & 10.493 & 1.767 & 1.979 \\
\hline A83-26 & 2.187 & 13.605 & 11.308 & 1.770 & 1.981 \\
\hline A83-27 & 2.264 & 12.889 & 10.830 & 1.768 & 1.980 \\
\hline A83-28 & 2.222 & 14.702 & 12.027 & 1.772 & 1.982 \\
\hline A83-29 & 2.258 & 17.444 & 13.767 & 1.777 & 1.985 \\
\hline A83-30 & 2.203 & 12.570 & 10.615 & 1.767 & 1.979 \\
\hline A83-31 & 2.170 & 12.787 & 10.762 & 1.768 & 1.980 \\
\hline A83-32 & 2.276 & 14.012 & 11.576 & 1.771 & 1.981 \\
\hline A83-33 & 2.238 & 14.772 & 12.072 & 1.772 & 1.982 \\
\hline A83-34 & 2.189 & 16.179 & 12.973 & 1.775 & 1.984 \\
\hline A83-35 & 2.261 & 12.363 & 10.475 & 1.767 & 1.979 \\
\hline
\end{tabular}

the applicability and prediction accuracy of the five methods. The sequence of the average pore-throat tortuosity values of all samples calculated by five methods is $\tau(\mathrm{Yu})>\tau$ (Chen) $>\tau$ (This study) $>$ $\tau$ (Plessis) $>\tau$ (Koponen). We can see that the value predicted by the new method falls in the center of the values predicted by the five methods, so it is thus possible to make a relatively objective prediction of permeability.

It needs to be pointed out that in the estimation process, " $n$ " in equation (3) was set from 0 to 1000 (in increments of 0.5). Practice 
Table 4

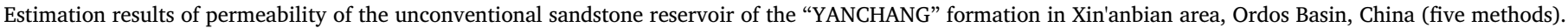

\begin{tabular}{|c|c|c|c|c|c|}
\hline Sample number & $K$ (This study) $/ 10^{-3} \mu \mathrm{m}^{2}$ & $K(\mathrm{Yu} \& \mathrm{Li}) / 10^{-3} \mu \mathrm{m}^{2}$ & $K($ Chen $) / 10^{-3} \mu \mathrm{m}^{2}$ & $K$ (Koponen) $/ 10^{-3} \mu \mathrm{m}^{2}$ & $K$ (Plessis) $/ 10^{-3} \mu \mathrm{m}^{2}$ \\
\hline A83-1 & 0.066 & 0.002 & 0.003 & 0.102 & 0.082 \\
\hline A83-2 & 0.029 & 0.000 & 0.001 & 0.044 & 0.035 \\
\hline A83-3 & 0.032 & 0.000 & 0.001 & 0.047 & 0.038 \\
\hline A83-4 & 0.075 & 0.003 & 0.004 & 0.115 & 0.092 \\
\hline A83-5 & 0.049 & 0.001 & 0.002 & 0.078 & 0.062 \\
\hline A83-6 & 0.075 & 0.003 & 0.004 & 0.116 & 0.092 \\
\hline A83-7 & 0.026 & 0.000 & 0.000 & 0.037 & 0.030 \\
\hline A83-8 & 0.016 & 0.000 & 0.000 & 0.024 & 0.019 \\
\hline A83-9 & 0.065 & 0.002 & 0.003 & 0.097 & 0.077 \\
\hline A83-10 & 0.058 & 0.002 & 0.003 & 0.094 & 0.075 \\
\hline A83-11 & 0.079 & 0.004 & 0.005 & 0.130 & 0.104 \\
\hline A83-12 & 0.031 & 0.000 & 0.001 & 0.050 & 0.040 \\
\hline A83-13 & 0.053 & 0.001 & 0.002 & 0.074 & 0.059 \\
\hline A83-14 & 0.055 & 0.001 & 0.002 & 0.086 & 0.068 \\
\hline A83-15 & 0.049 & 0.001 & 0.002 & 0.076 & 0.061 \\
\hline A83-16 & 0.044 & 0.001 & 0.001 & 0.071 & 0.057 \\
\hline A83-17 & 0.057 & 0.002 & 0.002 & 0.088 & 0.070 \\
\hline A83-18 & 0.050 & 0.001 & 0.001 & 0.073 & 0.058 \\
\hline A83-19 & 0.048 & 0.001 & 0.002 & 0.077 & 0.062 \\
\hline A83-20 & 0.070 & 0.003 & 0.004 & 0.110 & 0.088 \\
\hline A83-21 & 0.047 & 0.001 & 0.001 & 0.068 & 0.055 \\
\hline A83-22 & 0.055 & 0.001 & 0.002 & 0.083 & 0.067 \\
\hline A83-23 & 0.045 & 0.001 & 0.001 & 0.067 & 0.054 \\
\hline A83-24 & 0.042 & 0.001 & 0.001 & 0.069 & 0.055 \\
\hline A83-25 & 0.058 & 0.002 & 0.003 & 0.096 & 0.077 \\
\hline A83-26 & 0.061 & 0.002 & 0.002 & 0.092 & 0.074 \\
\hline A83-27 & 0.059 & 0.002 & 0.003 & 0.097 & 0.077 \\
\hline A83-28 & 0.046 & 0.001 & 0.002 & 0.072 & 0.058 \\
\hline A83-29 & 0.036 & 0.001 & 0.001 & 0.058 & 0.046 \\
\hline A83-30 & 0.062 & 0.002 & 0.003 & 0.097 & 0.077 \\
\hline A83-31 & 0.066 & 0.002 & 0.003 & 0.099 & 0.079 \\
\hline A83-32 & 0.052 & 0.001 & 0.002 & 0.086 & 0.069 \\
\hline A83-33 & 0.045 & 0.001 & 0.002 & 0.072 & 0.058 \\
\hline A83-34 & 0.047 & 0.001 & 0.001 & 0.072 & 0.057 \\
\hline A83-35 & 0.064 & 0.002 & 0.003 & 0.104 & 0.083 \\
\hline
\end{tabular}

shows that when $n$ is set to 1 , the accuracy is the best that could also be proved by the following data. It is believed that the parameter " $n$ " would be distinguished by the original properties of the reservoir.

In order to evaluate the accuracy and generalized performance of the five methods, including the "pore-throat divide-union" method, correlation analysis between permeability values in Table 4 and the porosity in Table 1 should be carried out. It was found to be characterized by the power function $K=\mathrm{ab}^{\mathrm{s}}$, as noted in Fig. 6 and Table 5 .

The correlation coefficients $R^{2}$ of the five fitting equation in Table 5

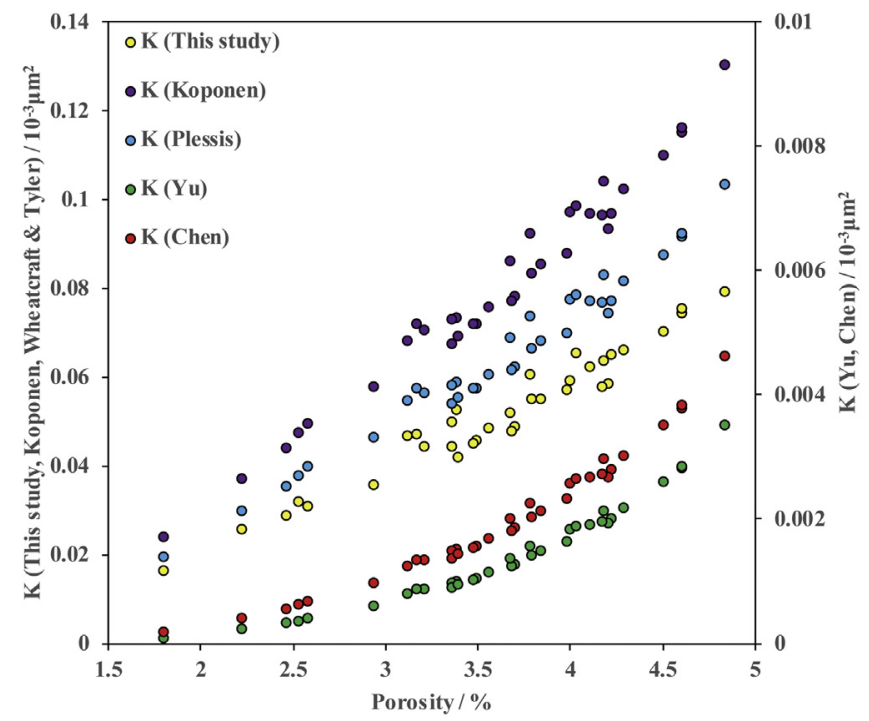

Fig. 6. Correlation of five types of permeability prediction value and porosity.
Table 5

Fitting constant of the power function in the correlation diagram of five types of permeability prediction value and porosity.

\begin{tabular}{llll}
\hline Permeability & $\begin{array}{l}\text { Power function } \\
\text { constant (a) }\end{array}$ & $\begin{array}{l}\text { Power function } \\
\text { index (b) }\end{array}$ & $\begin{array}{l}\text { Correlation } \\
\text { coefficient }\left(\mathrm{R}^{2}\right)\end{array}$ \\
\hline$K($ This study) $/ \mathrm{mD}$ & 0.0076 & 1.4879 & 0.9607 \\
$K($ Yu \& Li) $/ \mathrm{mD}$ & 0.00001 & 3.4827 & 0.9957 \\
$K($ Chen) $/ \mathrm{mD}$ & 0.00004 & 3.0729 & 0.9947 \\
$K($ Koponen $/ \mathrm{mD}$ & 0.0107 & 1.5612 & 0.9797 \\
$K($ Plessis $) / \mathrm{mD}$ & 0.0087 & 1.5487 & 0.9793 \\
\hline
\end{tabular}

are all above 0.95 , which will be applied to the following accuracy and generalization performance test, so as to verify the superiority of the new theoretical estimation method.

\section{Case application}

\subsection{Rapid determination on absolute permeability of tight oil reservoir}

The standard porosity and permeability test of the unconventional sandstone reservoir of the "YANCHANG" formation of Ordos Basin, China were carried out. The constants of five equations could be found in Table 5 so that we could generate permeability predictions of all samples, then compared the predicted results with measured results (Table 6), so as to verify the advantages and disadvantages of the five methods.

In order to prove the applicability and accuracy furtherly, some additional work should be carried out which is error analysis. First, the absolute values of the permeability differences between the measured values and the predicted values of the five methods should be 
Table 6

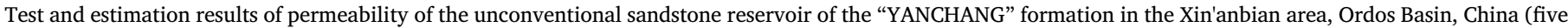
methods).

\begin{tabular}{|c|c|c|c|c|c|c|c|}
\hline Sample number & Porosity/\% & Permeability $/ 10^{-3} \mu \mathrm{m}^{2}$ & $\mathrm{~K}$ (This study) $/ 10^{-3} \mu \mathrm{m}^{2}$ & $\mathrm{~K}(\mathrm{Yu}) / 10^{-3} \mu \mathrm{m}^{2}$ & $K$ (Chen) $/ 10^{-3} \mu \mathrm{m}^{2}$ & $K$ (Koponen) $/ 10^{-3} \mu \mathrm{m}^{2}$ & $K$ (Plessis) $/ 10^{-3} \mu \mathrm{m}^{2}$ \\
\hline A83-36 & 5.64 & 0.014 & 0.100 & 0.004 & 0.008 & 0.159 & 0.127 \\
\hline A83-37 & 4.76 & 0.034 & 0.077 & 0.002 & 0.005 & 0.122 & 0.097 \\
\hline A83-38 & 1.61 & 0.008 & 0.015 & 0.000 & 0.000 & 0.023 & 0.018 \\
\hline A83-39 & 1.41 & 0.006 & 0.013 & 0.000 & 0.000 & 0.018 & 0.015 \\
\hline A83-40 & 8.4 & 0.108 & 0.180 & 0.017 & 0.028 & 0.297 & 0.235 \\
\hline A83-41 & 8.5 & 0.153 & 0.184 & 0.017 & 0.029 & 0.302 & 0.239 \\
\hline A83-42 & 7.8 & 0.044 & 0.161 & 0.013 & 0.022 & 0.264 & 0.209 \\
\hline A83-43 & 7.83 & 0.051 & 0.162 & 0.013 & 0.022 & 0.266 & 0.211 \\
\hline A83-44 & 4.52 & 0.049 & 0.072 & 0.002 & 0.004 & 0.113 & 0.090 \\
\hline A83-45 & 4.87 & 0.049 & 0.080 & 0.002 & 0.005 & 0.127 & 0.101 \\
\hline A83-46 & 3.95 & 0.022 & 0.059 & 0.001 & 0.003 & 0.091 & 0.073 \\
\hline A83-47 & 4.04 & 0.031 & 0.061 & 0.001 & 0.003 & 0.095 & 0.076 \\
\hline A83-48 & 4.33 & 0.010 & 0.067 & 0.002 & 0.004 & 0.105 & 0.084 \\
\hline A83-49 & 12.42 & 0.459 & 0.323 & 0.065 & 0.092 & 0.546 & 0.431 \\
\hline A83-50 & 9.41 & 0.032 & 0.214 & 0.025 & 0.039 & 0.354 & 0.280 \\
\hline A83-51 & 4.84 & 0.038 & 0.079 & 0.002 & 0.005 & 0.125 & 0.100 \\
\hline A83-52 & 7.49 & 0.039 & 0.152 & 0.011 & 0.019 & 0.248 & 0.197 \\
\hline A83-53 & 9.25 & 0.260 & 0.208 & 0.023 & 0.037 & 0.345 & 0.273 \\
\hline A83-54 & 11.35 & 0.803 & 0.282 & 0.047 & 0.070 & 0.475 & 0.374 \\
\hline A83-55 & 8.62 & 0.096 & 0.187 & 0.018 & 0.030 & 0.309 & 0.245 \\
\hline A83-56 & 6.67 & 0.033 & 0.128 & 0.007 & 0.014 & 0.207 & 0.164 \\
\hline Average & 6.56 & 0.111 & 0.134 & 0.013 & 0.021 & 0.219 & 0.173 \\
\hline
\end{tabular}

calculated respectively. Second, the average of the above five absolute values were calculated. Third, the average of the predicted values and the measured values were also calculated. Finally, the absolute values of the permeability differences between the average measured values and the average predicted values of the five methods should be calculated respectively (Table 6). The accuracy and generalization performance could be reflected by the above parameters.

As can be seen in Fig. 7, the two errors of the pore-throat divideunion method are both the smallest, respectively $0.023 \times 10^{-3} \mathrm{\mu m}^{2}$ and $0.090 \times 10^{-3} \mu^{2}$; the average values of other four methods were $0.090 \times 10^{-3} \mu \mathrm{m}^{2}$ and $0.108 \times 10^{-3} \mu \mathrm{m}^{2}$, respectively. Thus, the new method described in this study demonstrates superiority and accurate generalization performance as regards estimation of pore-throat tortuosity and reservoir permeability combined with Kozeny-Carman equation.

Tight reservoirs and other tight oil reservoirs are different from conventional reservoirs because of their complex accumulation mechanisms and poor physical properties. Therefore, the permeability should be closely integrated with experiment and theory, so that they can be evaluated objectively and reasonably.

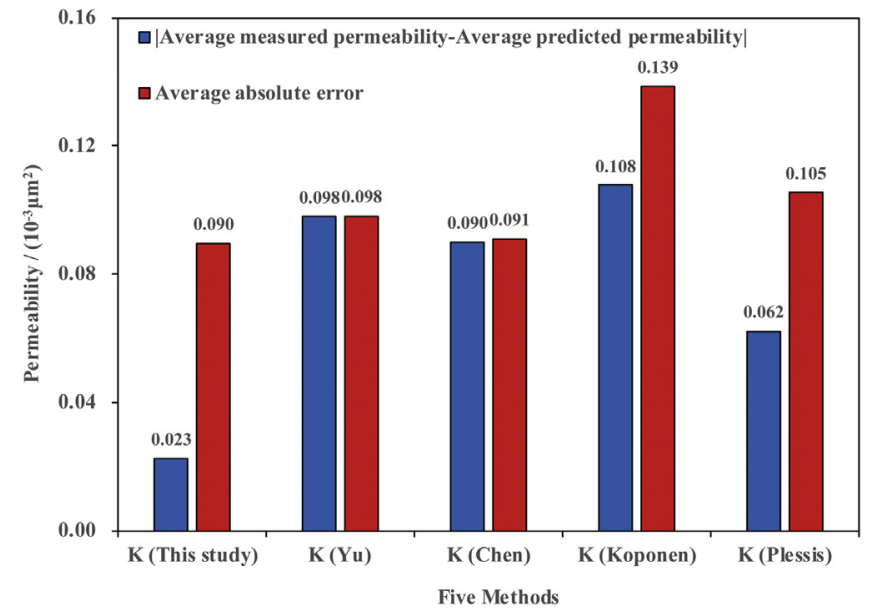

Fig. 7. Comparison of the methods' accuracy and generalization performance.

\subsection{Quantitative determination of permeability anisotropy in tight oil reservoir}

According to the requirement of "umbrella deconstruction" technology, field emission scanning electron microscopy (FIE-SEM) observation of reservoir slices in eight directions was carried out (Fig. 8). High-precision image processing was also carried out for reservoir imaging in eight directions by removing the invalid pore and throat. The dimensionless " $n$ " in equation (4) is taken as 1 , then the average radius, average length of major axis, average perimeter and pore-throat tortuosity were all calculated (Table 7). The permeability anisotropy can be quantitatively evaluated by plotting all the values into changing curves.

As can be seen from Fig. 9, the permeability curves of tight oil reservoir samples show that the permeability anisotropy of tight oil reservoir samples is remarkable. We could see that the sample has the highest permeability at the angle of $0^{\circ}\left(180^{\circ} / 360^{\circ}\right)$ and the permeability values are equal to $0.25 \times 10^{-3} \mu \mathrm{m}^{2}$. Similarly, the sample has the lowest permeability at the angle of $22.5^{\circ}\left(202.5^{\circ}\right), 90^{\circ}\left(270^{\circ}\right)$, and $112.5^{\circ}\left(292.5^{\circ}\right)$, the permeability values are all equal to $0.06 \times 10^{-3} \mu \mathrm{m}^{2}$. The extreme difference of permeability at different angles of the same sample (the ratio of maximum to minimum) could reach about 4 , which fully proves that there are dominant permeability zones in tight oil reservoirs and this could not be ignored in the relative research in petroleum exploration and development.

\section{Conclusion}

Most of the current estimation methods of pore-throat tortuosity are focused on the testing of simplified models, and the majority of experimental and numerical simulation methods could only be used in reservoirs with high to moderate porosity and permeability. The method which originated from the original concept of pore-throat tortuosity is few. Thus, it does not meet the needs of permeability prediction in tight reservoirs; more accurate prediction ideas and means need to be discovered.

The significance of the minerals that grow in the particle boundary in the seepage process of the fluids should never be ignored. We should pay much more attention to this point when we investigate the precise method of permeability estimation of an unconventional reservoir.

The new permeability prediction model and its simplified form in 

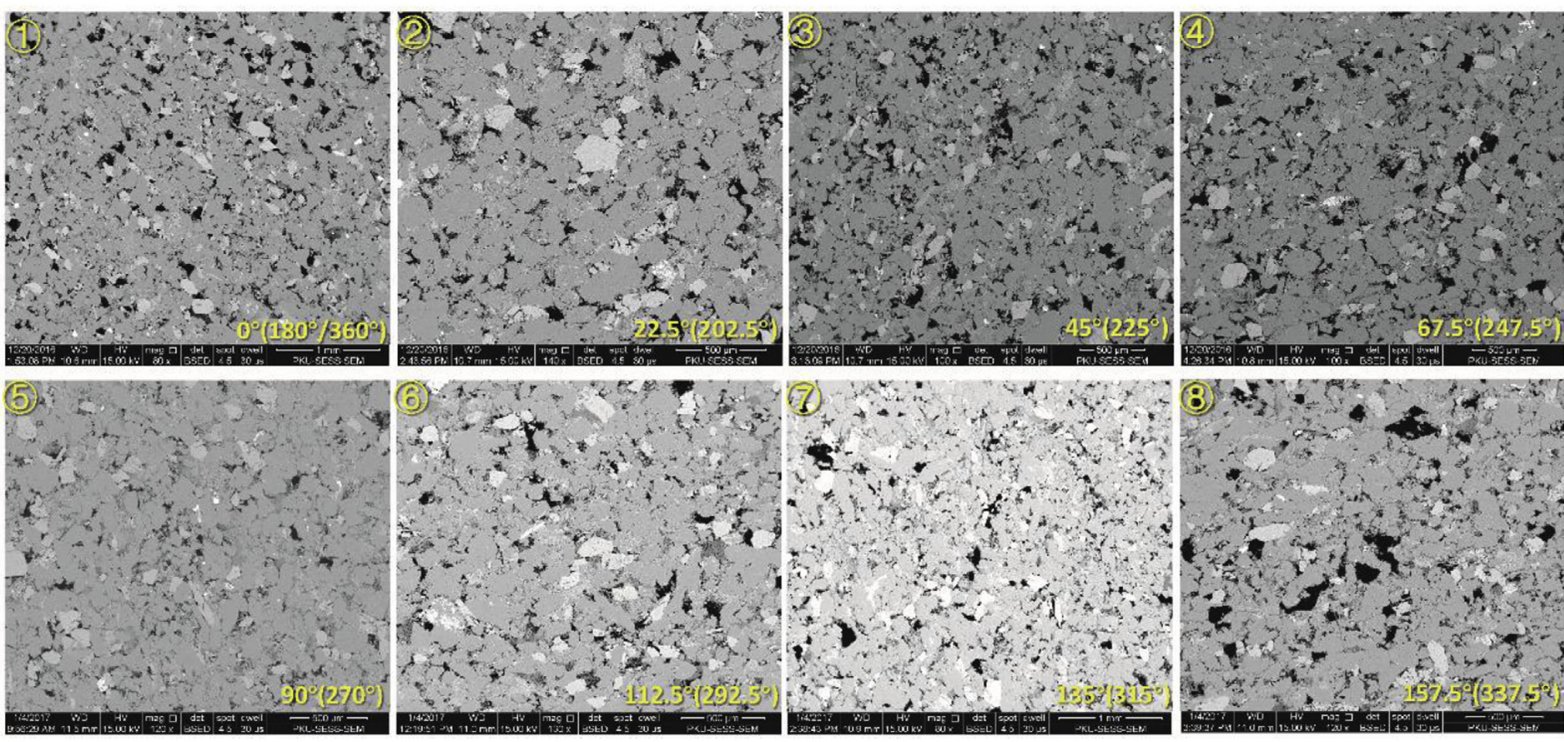

Fig. 8. High resolution FE-SEM images of tight oil reservoir samples using "Umbrella deconstruction" method (eight angels).

this study follows the original characteristics of the reservoir and then focuses closely on characteristics such as pore size and structure. In accordance with the principle of accurately describing the pore and throat in the full range, we calculated the pore-throat tortuosity of the unconventional reservoir under the multi-scale. The application in the unconventional sandstone reservoir of the "YANCHANG" formation in Xin'anbian area, Ordos Basin, China shows that the two errors of the new model which was proposed in this are the smallest of all methods examined so, combined with the Kozeny-Carman equation, the new method has demonstrated its superiority and robust generalization performance in estimating pore-throat tortuosity and reservoir permeability.

Finally, by combining the "umbrella deconstruction" method, we carry out the quantitative determination of permeability anisotropy in tight oil reservoir, which found that the permeability anisotropy of tight oil reservoir samples is very significant, and the extreme difference of permeability of the same sample at different angles (the ratio of maximum to minimum value) could reach 4 . It fully proves that there are predominant permeability zones in tight oil reservoirs, which could not be ignored in petroleum research. The conclusions can provide important theoretical evidence and methodological basis for the process of oil filling and seepage recovery.

\section{Acknowledgement}

This work is granted by open fund (No. PLC20190401) of state key laboratory of oil and gas reservoir geology and exploitation (Chengdu University of Technology) and the open fund project of the key Laboratory of Petroleum Resources Research, Institute of Geology and Geophysics, Chinese Academy of Sciences (No. KLOR2018-6). Thanks

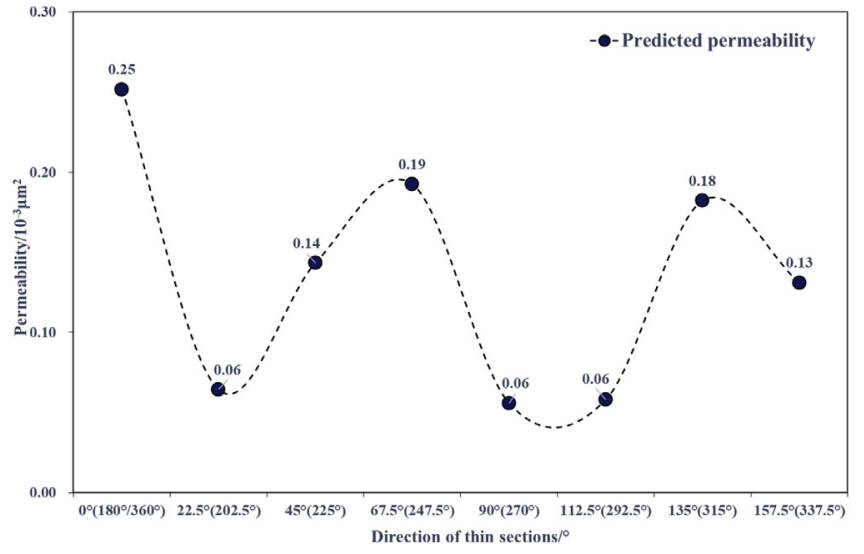

Fig. 9. The anisotropic permeability curve with the change of angles via precise pore-throat tortuosity characterization and "umbrella deconstruction" method.

for the important support of Professor Yapu Zhao, Quanzi Yuan and Assistant Professor Xianfu Huang in Institute of Mechanics, Chinese Academy of Sciences.

\section{Appendix A. Supplementary data}

Supplementary data to this article can be found online at https:// doi.org/10.1016/j.petrol.2019.03.009.

Table 7

Relative parameters of permeability calculation for tight oil reservoirs using "umbrella deconstruction" method and imaging processing.

\begin{tabular}{|c|c|c|c|c|c|c|c|}
\hline Sampling angel & Sampling number & Pore radius $/ \mu \mathrm{m}$ & Porosity/\% & Perimeter $/ \mu \mathrm{m}$ & Major axis/ $\mu \mathrm{m}$ & Pore-throat tortuosity & Permeability $/ 10^{-3} \mu \mathrm{m}^{2}$ \\
\hline $0^{\circ}\left(180^{\circ} / 360^{\circ}\right)$ & 1 & 7.79 & 11.21 & 43.50 & 12.89 & 3.38 & 0.25 \\
\hline $22.5^{\circ}\left(202.5^{\circ}\right)$ & 2 & 3.83 & 11.72 & 19.67 & 5.89 & 3.34 & 0.06 \\
\hline $45^{\circ}\left(225^{\circ}\right)$ & 3 & 5.55 & 12.80 & 30.51 & 8.86 & 3.44 & 0.14 \\
\hline $67.5^{\circ}\left(247.5^{\circ}\right)$ & 4 & 5.84 & 15.78 & 31.04 & 8.88 & 3.49 & 0.19 \\
\hline $90^{\circ}\left(270^{\circ}\right)$ & 5 & 4.34 & 7.75 & 25.03 & 7.65 & 3.27 & 0.06 \\
\hline $112.5^{\circ}\left(292.5^{\circ}\right)$ & 6 & 3.99 & 9.65 & 21.60 & 6.52 & 3.31 & 0.06 \\
\hline $135^{\circ}\left(315^{\circ}\right)$ & 7 & 7.28 & 8.95 & 40.20 & 12.37 & 3.25 & 0.18 \\
\hline $157.5^{\circ}\left(337.5^{\circ}\right)$ & 8 & 5.21 & 13.30 & 26.65 & 7.73 & 3.45 & 0.13 \\
\hline
\end{tabular}




\section{References}

An, S.Y., Yao, J., Yang, Y.F., Zhang, L., 2016. Influence of pore structure parameters on flow characteristics based on a digital rock and the pore network model. J. Nat. Gas Sci. Eng. 31, 156-163.

Arash, Rabbani, Saeid, Jamshidi, Saeed, Salehi, et al., 2014. An automated simple algorithm for realistic pore network extraction from micro-tomography images. J. Pet. Sci. Eng. 123, 164-171.

Arash, Rabbani, Shahab, Ayatollahi, Riyaz, Kharrat, et al., 2016. Estimation of 3-D pore network coordination number of rocks from watershed segmentation of a single 2-D image. Adv. Water Resour. 94, 264-277.

Arash, Rabbani, Ali, Assadi, Riyaz, Kharrat, et al., 2017. Estimation of carbonates permeability using pore network parameters extracted from thin section images and comparison with experimental data. J. Nat. Gas Sci. Eng. 42, 85-98.

Beckingham, L.E., Peters, C.A., Um, W., et al., 2013. 2D and 3D imaging resolution tradeoffs in quantifying pore throats for prediction of permeability. Adv. Water Resour. 62, 1-12 Part A.

Boundreau, B.P., 1996. The diffusive tortuosity of finite - grained un-lithified sediments. Geochem. Cosmochim. Acta 60, 3139-3142.

Carman, P.C., 1939. Permeability of saturated sands, soils and clays. J. Agric. Sci. 29 (2), 263-273.

Chen, L., Gai, D., Sun, G., et al., 2011. A simple calculation method of pore and throat tortuosity. In: Proceedings of the Twentieth National Conference on Structural Engineering.

Comiti, J., Sabiri, N.E., Montillet, 2000. Experimental characterization of flow regimes in various porous media-III: limit of Darcy's or creeping flow regime for Newtonian and purely viscous non - Newtonian fluids. Chem. Eng. Sci. 55, 3057-3061.

Du, S., Pang, S., Shi, Y., 2018a. A new and more precise experiment method for characterizing the mineralogical heterogeneity of unconventional hydrocarbon reservoirs. Fuel 232, 666-671.

Du, S., Pang, S., Shi, Y., 2018b. Quantitative characterization on the microscopic pore heterogeneity of tight oil sandstone reservoir by considering both the resolution and representativeness. J. Pet. Sci. Eng. 169, 388-392.

Du, S., Shi, G., Shi, Y., et al., 2019. Imaging-based characterization of perthite in the upper triassic Yanchang formation tight sandstone of the Ordos Basin, China. Acta Geol. Sin.-Engl avaliable online in. https://doi.org/10.1111/1755-6724.13768.

Huang, X., Zhao, Y., 2017. Characterization of pore structure, gas adsorption, and spontaneous imbibition in shale gas reservoirs. J. Pet. Sci. Eng. 159, 197-204.

Kenneth, Chukwuma, Emese, M. Bordy, Angelique, Coetzer, et al., 2018. Evolution of porosity and pore geometry in the Permian Whitehill Formation of South Africa - a FE-SEM image analysis study. Mar. Petrol. Geol. 91, 262-278.

Kirill, M. Gerke, Roman, V. Vasilyev, Siarhei, Khirevich, et al., 2018. Finite-difference method Stokes solver (FDMSS) for 3D pore geometries: software development, validation and case studies. Comput. Geosci. 114, 1-58.

Koponen, A., Kataja, M., Timonen, J., 1996. Tortuous flow in porous media. Phys. Rev. E. $54,406-410$.

Kozeny, J., 1927. Ueber kapillare Leitung des Wassers im Boden. Sitzungsber Akad. Wins, Wien 136 (2a), 271-306.

Li, C., Zhang, X., 2007. Unification of flow equations in tubes and in porous media. Xinjiang Pet. Geol 28 (2), 252-253.

London, M., Cameron, S.M., Donald, J., Wassmuth, F.R., 2014. Water-flooding Experiments with X-Ray CT Imaging. Society of Petroleum Engineers.
Lonnes, S., Angel, G., Holland, R.N.M.R., 2003. Petrophysical predictions on cores. In: 44th Annual Logging Symposium Transactions. Society of Petroleum Well Log Analysts.

Lv, D., 2000. Calculation and application of hydraulics tortuosity factor in porous media. Xinjiang Pet. Geol. 21 (6), 515-517.

Nishank, Saxena, Ronny, Hofmann, Faruk, O. Alpak, 2017a. References and benchmarks for pore-scale flow simulated using micro-CT images of porous media and digital rocks. Adv. Water Resour. 109, 211-235.

Nishank, Saxena, Ronny, Hofmann, Faruk, O. Alpak, et al., 2017b. Effect of image segmentation \& voxel size on micro-CT computed effective transport \& elastic properties. Mar. Petrol. Geol. 86, 972-990.

Patrick, William, Michael, Corbett, Haitao, Wang, et al., 2017. Using the porosity exponent $(\mathrm{m})$ and pore-scale resistivity modelling to understand pore fabric types in coquinas (Barremian-Aptian) of the Morro do Chaves Formation, NE Brazil. Mar. Petrol. Geol. 88, 628-647.

Plessis, J.P.D., Masliyah, J.H., 1988. Mathematical modelling of flow through consolidated isotropic porous media. Transport Porous Med 3 (2), 145-161.

Peng, R.D., Yang, Y.C., Ju, Y., et al., 2011. Computation of fractal dimension of rock pores based on gray CT images. Chin. Sci. Bull. 56, 3346.

Piela, K., Ooms, G., Sengers, J.V., 2009. Phenomenological description of phase inversion. Phys. Rev. 792 (Pt1), pp021403.

Rajkumar, K., Ramanathan, A.L., Behera, P.N., 2012. Characterization of clay minerals in the Sundarban mangroves river sediments by SEM/EDS. J. Geol. Soc. India 80, $429-434$.

Ren, X.X., Li, A.F., He, B.Q., et al., 2015. Influence of the pore structures on stress sensitivity of tight sandstone reservoir. Adv. Petrol. Explor. Dev. 10, 13-18.

Rhiannon, T. Lewis, John, Georg Seland, et al., 2016. A multi-dimensional experiment for characterization of pore structure heterogeneity using NMR. J. Magn. Reson. 263, 19-32.

Rikan, Kareem, Pablo, Cubillas, Jon, Gluyas, et al., 2017. Multi-technique approach to the petrophysical characterization of Berea sandstone core plugs (Cleveland Quarries, USA). J. Pet. Sci. Eng. 149, 436-455.

Sen, P.N., Scala, C., Cohen, M.H., 1981. A self-similar model for sedimentary - rocks with application to the dielectric - constant of fused glass -beads. Geophysics 46, 781-795.

Shah, S.M., Gray, F., Crawshaw, J.P., et al., 2016. Micro-computed tomography pore-scale study of flow in porous media: effect of voxel resolution. Adv. Water Resour. 95, 276-287.

Song, W., Yao, J., Yang, L., et al., 2017. New pore size distribution calculation model based on chord length and digital image. J. Nat. Gas Sci. Eng. 48, 111-118.

Song, W.H., Yao, J., Ma, J.S., et al., 2018. Pore-scale numerical investigation into the impacts of the spatial and pore-size distributions of organic matter on shale gas flow and their implications on multiscale characterization. Fuel 216, 707-721.

Xiong, F., Jiang, Z., Zhang, L., 2016. The role of the residual bitumen in the gas storage capacity of mature lacustrine shale: a case study of the Triassic Yanchang shale, Ordos Basin, China. Mar. Petrol. Geol. 69, 205-215.

Yang, Y.F., Zhang, W.J., Gao, Y., et al., 2016. Influence of stress sensitivity on microscopic pore structure and fluid flow in porous media. J. Nat. Gas Sci. Eng. 36, 20-31 Part A.

Yang, X., Meng, Y., Shi, X., et al., 2017. Influence of porosity and permeability heterogeneity on liquid invasion in tight gas reservoirs. J. Nat. Gas Sci. Eng. 37, 169-177.

Yu, B.M, Li, J.H., Li, Z.H., Zou, M.Q., 2003. Permeabilities of unsaturated fractal porous media. Int. J. Multiph. Flow 29, 1625-1642. 